Disclosure of Interest: None declared

DOI: 10.1136/annrheumdis-2017-eular.6909

\section{SAT0049 21ST CENTURY STATE OF RHEUMATOID ARTHRITIS MANAGEMENT IN THE UK}

A.L. $\operatorname{Tan}^{1}$, M. Buch ${ }^{1}$, D. O'Reilly ${ }^{2}$, T. Sheeran ${ }^{3}$, A. Bishop-Bailey ${ }^{4}$, G. Nock $^{4}$, S. Chitale ${ }^{5}$, P. Emery ${ }^{1} .{ }^{1}$ NIHR Leeds Musculoskeletal Biomedical Research Unit, Chapel Allerton Hospital, Leeds Institute of Rheumatic and Musculoskeletal Medicine, University of Leeds, Leeds; ${ }^{2}$ West Suffolk NHS Foundation Trust, West Suffolk Hospital, Bury Saint Edmunds; ${ }^{3}$ Rheumatology, Cannock Chase Hospital, Royal Wolverhampton Trust, Cannock; ${ }^{4} \mathrm{pH}$ Associates, $\mathrm{pH}$ Associates, Marlow; ${ }^{5}$ Rheumatology, Peter Maddison Rheumatology Centre, North Wales, Llandudno, United Kingdom

Background: The rheumatoid arthritis (RA) Treat to Target (T2T) recommendations ${ }^{1}$ defined in 2010 aimed to support clinicians to achieve optimal therapeutic outcomes for their patients.

Objectives: 38 hospitals prospectively audited management of newly diagnosed RA patients to determine compliance with the T2T recommendations and therapeutic outcomes achieved.

Methods: From April 2012 to September 2016 and upon diagnosis of RA, data on disease history, management and clinical outcomes were collected prospectively in a web based tool. Follow up to date provides data for up to 24 months from diagnosis (baseline).

Results: 1571 patients were recruited in 38 centres, with 12 months' follow up for 713 patients and of these 269 also had 24 months' follow up. 1021 (65\%) patients were female and $1360(87 \%)$ had a treatment target documented at baseline (1235 [79\%] disease activity score 28 (DAS28) remission and 125 [8\%] low disease activity state (LDAS)). DAS28 remission is defined as DAS28 $<2.6$, LDAS is defined as DAS28 $\geq 2.6<3$.2. Median baseline DAS28 scores were 4.9 and 5.3 for patients having a DAS28 remission and LDAS target, respectively. The table shows DAS28 scores at baseline, 12 and 24 months, and disease management received for the subset of patients with available DAS28 scores at the relevant time points, stratified by those who did/did not achieve their remission target and those with/without sustained remission at 24 months. Of the 108 patients eligible to receive biologic therapy, according to NICE guidance, $39(36 \%)$ received a biologic within their first 24 months of treatment.

\begin{tabular}{|c|c|c|c|c|}
\hline & \multicolumn{2}{|c|}{$\begin{array}{c}\text { Patients with 12 months follow up } \\
(n=71)\end{array}$} & $\begin{array}{c}\text { Patients with 24 months follow } \\
\text { up } \\
(n=269)\end{array}$ \\
\cline { 2 - 5 } & $\begin{array}{c}\text { In remission at } \\
12 \text { months } \\
{[n=276]}\end{array}$ & $\begin{array}{c}\text { Not in remission } \\
\text { at } 12 \text { months } \\
{[n=239]}\end{array}$ & $\begin{array}{c}\text { Sustained } \\
\text { remission at 24 } \\
\text { months [n=32] }\end{array}$ & $\begin{array}{c}\text { Remission not } \\
\text { sustained at } \\
24 \text { months } \\
\text { [n=96] }\end{array}$ \\
\hline
\end{tabular}

$\%$ patients compliant with $\mathrm{TT}$ standards

\begin{tabular}{|c|c|c|c|c|}
\hline $\begin{array}{c}\text { N (\%) with baseline } \\
\text { target set (remission or } \\
\text { LDAS) }\end{array}$ & $244(88 \%)$ & $183(77 \%)$ & $29(91 \%)$ & $76(79 \%)$ \\
\hline $\begin{array}{c}\mathrm{N}(\%) \text { with >4 visits in } \\
\text { the first year of } \\
\text { management }\end{array}$ & $207(75 \%)$ & $175(73 \%)$ & $31(97 \%)$ & $81(84 \%)$ \\
\hline $\begin{array}{c}\mathrm{N}(\%) \text { with >4 DAS scores } \\
\text { in the first year of } \\
\text { management }\end{array}$ & $180(65 \%)$ & $155(65 \%)$ & $24(75 \%)$ & $48(50 \%)$ \\
\hline $\begin{array}{c}\mathrm{N}(\%) \text { with dual therapy } \\
\text { within } 6 \text { months of } \\
\text { diagnosis }\end{array}$ & $148(54 \%)$ & $154(64 \%)$ & $17(53 \%)$ & $53(55 \%)$ \\
\hline
\end{tabular}

Disease scores

\begin{tabular}{|c|c|c|c|c|}
\hline $\begin{array}{c}\text { median baseline DAS28 } \\
\text { (n with available score) }\end{array}$ & $4.6[n=226]$ & $5.1[n=193]$ & $4.5[n=26]$ & $5.3[n=67]$ \\
\hline $\begin{array}{c}\text { median 12 month DAS28 } \\
\text { (n with available score) }\end{array}$ & $1.9[n=276]$ & $3.9[n=239]$ & $1.9[n=23]$ & $2.9[n=63]$ \\
\hline $\begin{array}{c}\text { median 24 month DAS28 } \\
\text { (n with available score) }\end{array}$ & $2.1[n=43]$ & $3.4[n=43]$ & $1.6[n=32]$ & $3.0[n=96]$ \\
\hline
\end{tabular}

Conclusions: The results suggest that more patients with a target set at baseline are in remission at 12 months and at 24 months than those without a target set. Number of visits, number of DAS28 scores and starting dual therapy within 6 months do not appear to affect the proportion of patients in remission at 12 months, but active management in the first 12 months ( $>4$ visits, $>4$ DAS28 scores) does appear to be associated with more patients in remission at 24 months. Thus we conclude that treating RA early and aggressively, in line with the T2T guidelines, leads to sustained clinical improvement.

References:

[1] Smolen et al. Treating rheumatoid arthritis to target: recommendations of an international task force. Ann Rheum Dis 2010;69:631-637.

Disclosure of Interest: A. L. Tan Consultant for: I have received honoraria from AbbVie Ltd., M. Buch Consultant for: has received previous honorarium/consultancy with Abbvie, Astra Zeneca, Bristol-Myers Squibb, Lilly, RocheChugai, Sandoz and research grants from Roche and Pfizer., D. O'Reilly Consultant for: has been paid research/consultancy fees/other honoraria by
Amgen, Abbvie, MSD, pH Associates, Roche, UCB and Wyeth., T. Sheeran Consultant for: has been paid consultancy fees by Roche, AbbVie, Novatis and Pfizer. A. Bishop-Bailey Employee of: I am an employee of $\mathrm{pH}$ Associates, the company commissioned by Abbvie to design and implement the study, as well as perform analysis and presentation/publication of the study data., G. Nock Employee of: I am an employee of $\mathrm{pH}$ Associates, the company commissioned by Abbvie to design and implement the study, as well as perform analysis and presentation/publication of the study data., S. Chitale Consultant for: has been on an advisory board for Abbvie and Pfizer, and has received educational grants from Abbvie, Pfizer and UCB., P. Emery Consultant for: undertaken clinical trials and provided expert advice to Pfizer,MSD,Abbvie,BMS,UCB,Roche,Novartis,Samsung, Sandoz and Lilly

DOI: 10.1136/annrheumdis-2017-eular.4740

\section{SAT0050 EARLY RESPONSE TO CERTOLIZUMAB PEGOL IN RHEUMATOID ARTHRITIS PREDICTS OUTCOME: DATA FROM A PROSPECTIVE OBSERVATIONAL STUDY}

A. Saraux ${ }^{1}$, R.M. Flipo ${ }^{2}$, F. Fagnani ${ }^{3}$, J. Massol ${ }^{4}$, B. Combe ${ }^{5}$, P. Huot-Marchand ${ }^{6}$, J.M. Joubert ${ }^{7}$, J. Dunkel ${ }^{8}$, G. Cukierman ${ }^{7}$. ${ }^{1}$ C.H.U. la Cavale Blanche, Brest; ${ }^{2}$ C.H.U. Hôpital Roger Salengro, Lille; ${ }^{3}$ Cemka Eval, Bourg-la-Reine; ${ }^{4}$ Phisquare, Besançon; ${ }^{5}$ C.H.U. Lapeyronie, Montpellier; ${ }^{6} \mathrm{MAPI}$, Lyon; ${ }^{7}$ UCB Pharma, Colombes, France; ${ }^{8}$ UCB Pharma, Monheim, Germany

Background: Treat-to-target strategies for rheumatoid arthritis (RA) require reliable clinical markers of treatment response in order to adapt therapy. Markers of early treatment failure can be used to ensure that patients (pts) are not unnecessarily exposed to ineffective therapy. Data from interventional clinical trials suggest that early clinical measures of disease activity (such as CDAl, DAS28 or HAQ-DI) after 12 weeks (wks) of treatment can reliably predict treatment failure at 1 year $(\mathrm{yr}) .^{1-3}$ However, it is unknown how such indicators perform in real-world settings.

Objectives: To evaluate the performance of clinical markers of early treatment failure (Wk12) as predictors of treatment failure at 1yr in everyday clinical practice. Methods: Data from a 1yr interim analysis of the ECLAIR study were used: a longitudinal, prospective, observational, multicentre study of pts with RA starting treatment with certolizumab pegol (CZP) in France. Pts were evaluated at study entry and thereafter at 3-monthly routine consultations. Disease activity was assessed at each visit using CDAI, DAS28 and HAQ-DI. At Wk12, pts with missing data or no longer taking CZP were excluded from the analyses. Linear interpolation, LOCF or NRI were used to impute missing data at $1 \mathrm{yr}$, including data from pts who left the study early. Different definitions for treatment non-response were applied based on CDAI or $\triangle \mathrm{DAS} 28$ and $\triangle \mathrm{HAQ}$-DI relative to pre-treatment values. Non-response at Wk12 was defined as $\mathrm{CDAl}>10, \triangle \mathrm{DAS} 28<1.2$ or $\triangle \mathrm{HAQ}-\mathrm{DI}<0.22$. Then, failure at $1 \mathrm{yr}$ was defined as $\mathrm{CDAl}>22, \mathrm{DAS} 28>3.2$ and $\mathrm{HAQ}-\mathrm{DI}>0.5$. Positive predictive values (PPV; proportion of treatment failures at $1 \mathrm{yr}$ in Wk12 non-responders) were used to evaluate the predictive performance of each tool.

Results: Overall, 792 pts were enrolled and data from 730 pts analysed. Performance of CDAl at predicting treatment failure at 1yr was assessed in 532 pts (198 data values missing at Wk12). Response and failure rates at Wk12 and $1 \mathrm{yr}$ are presented (see Table). The PPV for CDAI was $88.8 \%$, indicating that almost $9 / 10$ pts identified as non-responders at Wk12 fail to respond at $1 \mathrm{yr}$. Specificity was also high $(96.0 \%)$, indicating that $<5 \%$ of pts who achieved CDAI response at $1 \mathrm{yr}$ were non-responders at Wk12. Similar analyses performed for DAS28 and HAQ-DI produced PPVs of $69.0 \%$ and $75.4 \%$, respectively.

Table: Response and failure rates of CZP-treated patients at Week 12 and 1 year

\begin{tabular}{|c|c|c|c|}
\hline & \multicolumn{3}{|c|}{ CDAl at 1 year } \\
\hline CDAl at Week 12 & $>22$ (Failure) & $\leq 22$ (Response) & Total \\
\hline$>10$ (Non-response) & 79 & 10 & 89 \\
\hline$\leq 10$ (Responøe) & 205 & 238 & 443 \\
\hline \multirow[t]{3}{*}{ Total } & 284 & 248 & 532 \\
\hline & \multicolumn{3}{|c|}{ Sensitivity $=27.8 \%$, Specificity $=96.0 \%, P P V=88.8 \%, N P V=53.7 \%$} \\
\hline & \multicolumn{3}{|c|}{ DAS28 at 1 year } \\
\hline$\triangle \mathrm{DAS} 28$ at Week 12 & $>32$ (Failure) & $\leq 3.2$ (Response) & Total \\
\hline$<1.2$ (Non-response) & 136 & 61 & 197 \\
\hline$\geq 1.2$ (Response) & 102 & 135 & 237 \\
\hline \multirow[t]{3}{*}{ Total } & 238 & 196 & 434 \\
\hline & \multicolumn{3}{|c|}{ Sensitivity $=57.1 \%$, Specificity $=68.9 \%, P P V=69.0 \%, N P V=57.0 \%$} \\
\hline & & $\mathrm{HAQ}-\mathrm{Dl}$ at 1 year & \\
\hline$\triangle \mathrm{HAQ}-\mathrm{DI}$ at Week 12 & $>0.5$ (Fallure) & $\leq 0.5$ (Response) & Total \\
\hline$<0.22$ (Non-response) & 175 & 57 & 232 \\
\hline$\geq 0.22$ (Response) & 154 & 110 & 264 \\
\hline Total & 329 & 167 & 496 \\
\hline
\end{tabular}

CDAI:Clinical Disease Activity Index; DAS28: Disease Activity Score; HAQ-DI:Heath Assesement Questionnare-Disability Index; NPV: Negative predictivevalue; PPV: Positive predictive value.

Conclusions: The PPV describing the performance of early CDAI measure as a 
predictor of treatment failure at 1yr among CZP-treated RA pts was high; $88.8 \%$ of pts identified as non-responders at Wk12 will represent a treatment failure at 1yr. Simple tools such as CDAl, assessed during routine consultations, may be reliable markers to predict treatment failure without need for complementary biological tests.

References:

[1] Keystone EC. J Rheumatol 2011;38:990-6.

[2] Curtis JR. Arth Care Res 2012;64:658-67.

[3] van der Heijde D. J Rheumatol 2012;39:1326-33.

Acknowledgements: This study was funded by UCB Pharma. We thank the patients and their caregivers in addition to the investigators and their teams who contributed to this study. We also thank Isabelle Bru (UCB Pharma) who helped conduct the ECLAIR study. Editorial services were provided by Costello Medical Consulting.

Disclosure of Interest: A. Saraux Consultant for: UCB Pharma, R. M. Flipo Consultant for: UCB Pharma, F. Fagnani Consultant for: UCB Pharma, J. Massol: None declared, B. Combe Grant/research support from: Merck Pfizer Inc, RocheChugai, Consultant for: Merck, Pfizer, Roche-Chugai, UCB Pharma, Bristol-Myers Squibb, Celgene, Eli Lilly, Speakers bureau: Merck, Pfizer, Roche-Chugai, UCB Pharma, Bristol-Myers Squibb, Celgene, Eli Lilly, Novartis, P. Huot-Marchand: None declared, J. M. Joubert Employee of: UCB Pharma, J. Dunkel Employee of: UCB Pharma, G. Cukierman Employee of: UCB Pharma

DOI: 10.1136/annrheumdis-2017-eular.1974

\section{SAT0051 CITRULLINATION OF ADENOSINE DEAMINASE ISOFORMS IN RHEUMATOID ARTHRITIS}

S. Sharoyan ${ }^{1}$, L. Karapetyan ${ }^{1}$, R. Harutyunyan ${ }^{2}$, S. Mardanyan ${ }^{1}$, A. Antonyan ${ }^{1}$ ${ }^{1}$ H.Ch. Buniatian Institute of Biochemistry of Armenian NAS; " "Yerevan" Medical Center, Yerevan, Armenia

Background: One of the most important discoveries in rheumatology is the characterization of citrulline containing auto-antigens [1]. The identification of citrullinated proteins as auto-antigens and the development of new assay based on the detection of anti-citrullinated protein antibodies (ACPAs) become a breakthrough in the diagnosis and treatment of rheumatoid arthritis (RA). Mitsui and coauthors in vitro identified adenosine deaminase (ADA) as an ACPA antigen [2]. Earlier we have reported the enhance of ADA activity in synovial fluids (SFs) of RA patients [3].This increasing was in correlation with the ratio of small isoenzyme (SADA) to the large (LADA) [4].The comparison of citrullination states of SADA and LADA can be a clue for understanding the mechanism of SADA/LADA increase in RA, which is important both in diagnosis and treatment of the disease.

Objectives: The objectives of this study were a) to separate SADA and LADA isoforms from SFs of RA patients and $b$ ) to compare their citrullination degree. Methods: The SADA and LADA isoforms from SFs of RA patients were separated and purified using gel-filtration and ion-exchange chromatography [4]. The citrullination degree of the isoforms was measured in the colorimetric assay with diacetylmonoxime (DAMO) [6] using the absorbance at $530 \mathrm{~nm}$ and free L-citrulline as a standard.

Results: The SF samples of 20 RA patients with initial ADA activity in the range 35-190 IU/L were used. Earlier we demonstrated a negligible level of SADA at initial ADA lower of this interval. In the samples with medium initial activity (35-55 IU/L), SADA/LADA ratio was $\approx 1 / 2$. In those with high ADA activity (100-190 IU/L) this ratio was $\approx 4$. The separation and purification of LADA from 10 SFs revealed that it is not citrullinated in any case. In SADA from SFs with medium ADA activity, we failed to register the citrullination. In SADA from SFs with the initial ADA activity $\geq 100 \mathrm{IU} / \mathrm{L}$, the significant citrullination $(\approx 0.6 \mu \mathrm{mol} / \mathrm{mg}$ of protein) was registered.

Conclusions: The obtained results evidence that SADA from SFs with high ADA activity can serve as new citrulline containing ACPA antigen. This finding can be a base of developing new strategy (e.g. seeking specific inhibitors) for treatment of RA patients because citrullination enhances the ADA activity [2], hampering the increase of adenosine by methotrexate.

References:

[1] vanVenrooij WJ, van Beers JJ, Pruijn GJ. Anti-CCP Antibody, a Marker for the Early Detection of Rheumatoid Arthritis. Ann NY Acad Sci.1143:268-85, 2008.

[2] Mitsui H, Arito M, Sato T, Yokoyama MK, Suematsu N, et al. Novel anticitrullinated peptide autoantibodies identified by proteomics with in vitro citrullinated proteins in patients with rheumatoid arthritis. Inflammation and Regeneration 33:121-30, 2013.

[3] Antonyan A, Sharoyan S, Haroyan A, Harutyunyan R, Mardanyan S. Adenosine Deaminase activity in synovial fluid at arthritis. Proceedings of YSU. Chemistry and Biology 3:28-32, 2013

[4] Antonyan A, Sharoyan S, Haroyan A, Harutyunyan R, Mardanyan S. Adenosine Deaminase Isoforms in synovial fluid at Rheumatoid arthritis. Proceedings of YSU. Chemistry and Biology 2:54-57, 2014.

[5] Boyde TR, Rahmatullah M. Optimization of conditions for the colorimetric determination of citrulline, using diacetylmonoxime. Anal Biochem 107:424$431,1980$.

Disclosure of Interest: None declared

DOI: 10.1136/annrheumdis-2017-eular.1433

\section{SAT0052 HIGH CHANCE OF COMPREHENSIVE DISEASE CONTROL (CDC) IN VERY EARLY AND NORMAL WEIGHT RHEUMATOID ARTHRITIS PATIENTS TREATED ACCORDING TO THE TREAT TO TARGET STRATEGY}

A.L. Fedele, L. Petricca, B. Tolusso, S. Alivernini, C. Di Mario, G. Di Sante, G. Ferraccioli, E. Gremese. Institute of Rheumatology, Fondazione Policlinico Universitario A. Gemelli, Rome, Italy

Background: The ultimate goal for Rheumatoid Arthritis (RA) management is the simultaneous achievement of all clinical, functional and structural efficacy, i.e. comprehensive disease control (CDC) [1].

Objectives: To evaluate the effective chance and the consequences of $\mathrm{CDC}$ achievement in real world practice of Early Arthritis Clinic (EAC).

Methods: A total of 349 early rheumatoid arthritis (ERA) patients with a disease duration of less than 12 months were enrolled in the study. ERA patients fulfilled the 2010 ACR criteria for RA and were followed according to the treat-to-target strategy. Subjects with symptom duration less than 3 months were defined as having "very early RA" (VERA). The mean follow-up (FU) was $38.2 \pm 32.8$ months. At baseline, and every three months, the ACR/EULAR core data set variables were recorded. At baseline and every year hand and foot radiographs were examined according to modified Total Sharp score (mTSS). At each visit, clinical improvement and remission were evaluated according to EULAR criteria. The achievement of CDC (28-joint Disease Activity Score using $C$ reactive protein $<2.6$, Health Assessment Questionnaire $<0.5$ and change from baseline in $\mathrm{mTSS}$ $\leq 0.5$ ) was assessed every year of follow-up.

Results: At the twelfth month of FU 148 (42.4\%) ERA patients achieved CDC, while at the time of last FU $228(65.3 \%)$ subjects reached this target.

Patients achieving CDC at the 12th month of FU were younger $(p=0.05)$, in higher percentage male $(p=0.004)$, and with a normal weight (body mass index, BMI $<25)(p=0.003)$ and had a shorter disease duration, comprising a greater number of VERA $(p=0.01)$, compared to subjects not achieving disease control. There were no differences concerning autoantibody positivity and presence of erosions at onset between the two analyzed cohorts. Adjusting the analysis for age, the variables that arose as independent predictors of CDC at the 12th month of FU were a disease duration less than 3 months [OR $(95 \% \mathrm{Cl}): 1.97(1.23-3.14)]$ and a normal BMI [OR (95\% Cl): 2.05 (1.32-3.21)].

In our cohort, $105(30.1 \%)$ ERA patients were treated with biological disease modifying anti-rheumatic drugs (bDMARDs) over time. Biotechnological therapy was less frequently started by subjects in CDC, both after 12 months $(p=0.003)$ and at the time of last FU $(p<0.0001)$. At the multivariate analysis, not achieving $\mathrm{CDC}$ at the 12th month of FU [OR (95\% Cl): 2.69 (1.59-4.57)] and a BMI $\geq 25$ [OR $(95 \% \mathrm{Cl}): 2.05(1.23-3.42)]$ were the variables significantly associated to bDMARD therapy over time.

Conclusions: The simultaneous achievement of symptom control, inhibition of radiographic progression and normalization of function, is a feasible target in real word EAC. Having a VERA and a normal weight are associated to a high chance of "deep" remission.

References:

[1] Emery P, et al. Ann Rheum Dis 2015; 74: 2165-2174.

Disclosure of Interest: None declared

DOI: 10.1136/annrheumdis-2017-eular.5496

\section{SAT0053 THE INCIDENT IMMUNOLOGICAL STATUS PREDICTS DRUG-FREE DISEASE FLARE IN RHEUMATOID ARTHRITIS PATIENTS ACHIEVING STRINGENT CLINICAL AND ULTRASONOGRAPHIC CONTROL OF THE PERIPHERAL INFLAMMATORY PROCESS}

A. Manzo, S. Bugatti, F. Benaglio, B. Vitolo, G. Sakellariou, R. Caporali, C. Montecucco. Rheumatology and Translational Immunology Research Laboratories (LaRIT), Division of Rheumatology, IRCCS Policlinico San Matteo Foundation/University of Pavia, Pavia, Italy

Background: The development of predictive tools to evaluate health risks and design personalized health plans in patients with rheumatoid arthritis (RA) achieving remission still represents a major unmet need. In this perspective, the relative weight of clinical, ultrasound and immunological assessment of disease characteristics for predicting recurrence of the inflammatory process under drug-free conditions remains unclear.

Objectives: To investigate the predictive value of baseline clinical remission stringency, synovial power Doppler (PD) ultrasound indices and the incident autoimmune status, as predictors of flare under drug-free conditions after a DAS28-driven treatment strategy with methotrexate (MTX) in early RA.

Methods: 85 RA patients achieving stable remission and candidate to MTX withdrawal were recruited according to the following criteria: 1) introduction of MTX within 12 months from symptoms' onset, 2) at least 24 months of MTX treatment with a DAS28-driven protocol targeting low disease activity (LDA), 3) DAS28 $<2.6$ for $>6$ months in the absence of corticosteroids. Following treatment suspension, patients were monitored at three months' intervals across 24 months through clinical, ultrasound (hands-feet-axillary lymph nodes), radiographic and immunologic screenings (ACPA-RF status, CXCL13 circulating levels [1-2] and FACS analysis for quantification of Ki67+/regulatory T-B cell subsets). Treatment was re-introduced in case of DAS28 $\geq 3.2$ or stable LDA. 